International Journal of Engineering Applied Sciences and Technology, 2019

Vol. 4, Issue 3, ISSN No. 2455-2143, Pages 349-352

Published Online July 2019 in IJEAST (http://www.ijeast.com)

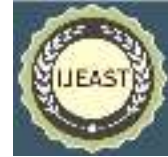

\title{
EXPERIMENTAL INVESTIGATION FOR EFFECT OF CHOPPED GLASS FIBRES ON THE STRENGTH OF CONCRETE
}

\author{
Joginder \\ M.tech Student, Department of civil \\ Engineering, \\ Ganga Institute of Technology \& Management \\ (MDU) Haryana, INDIA
}

\begin{abstract}
The effect of glass fibre on flexural strength, split-tensile strength and compressive strength was studied for different fiber content on M20 grade concrete designed as per IS 10262.The maximum size of aggregates used was $20 \mathrm{~mm}$. To study the effect on compressive strength, flexural strength, split-tensile strength 6 cubes, 6 prisms and 6 cylinders were casted and tested. After that a practical application of GFRC in the form of cement concrete tiles was taken into consideration and no special technique was used to produce this tiles. The thickness of the tiles was $20 \mathrm{~mm}$ and maximum size of aggregates used was $8 \mathrm{~mm}$. The water cement ratio was kept consistent and the admixture content was varied from .8 to 1.5 percent to maintain slump in between $50 \mathrm{~mm}$ to $100 \mathrm{~mm}$. The mix proportion used was 1:1.78:2.66. The size of short fibres used were $30 \mathrm{~mm}$ and the glass fibres were alkali resistant. The effect of this short fibres on wet transverse strength, compressive strength and water absorption was carried out. Six full sized tiles $400 \mathrm{~mm}$ $* 400 \mathrm{~mm} * 20 \mathrm{~mm}$ were tested and the results recorded. Pulse velocity tests was also conducted.
\end{abstract}

Keyword: GFRC, AR glass fibre, AN fibres, FRP

\section{INTRODUCTION}

Glass fibre reinforced concrete (GFRC) is a cementitous composite product reinforced with discrete glass fibres of varying length and size. The glass fibre used is alkaline resistant as glass fibre are susceptible to alkali which decreases the durability of GFRC. Glass strands are utilized for the most part for outside claddings, veneer plates and different components where their reinforcing impacts are

\author{
Mrs. Sheela Malik \\ Assistant Professor, Department of Civil \\ Engineering, \\ Ganga Institute of Technology \& Management \\ (MDU) Haryana, INDIA
}

required during construction. GFRC is stiff in fresh state has lower slump and hence less workable, therefore water reducing admixtures are used. Further the properties of GFRC depends on various parameters like method of producing the product. It can be done by various methods like spraying, casting, extrusion techniques etc. Cement type is also found to have considerable effect on the GFRC. The length of the fibre, sand/filler type, cement ratio methods and duration of curing also effect the properties of GFRC.

\section{Applications:}

- The main area of FRC applications are as follows

- Runway, Aircraft Parking and Pavements

- Tunnel lining and slope stabilization

- Blast Resistant structures

- Thin Shell, Walls, Pipes, and Manholes

- Dams and Hydraulic Structure

- Different Applications include machine tool and instrument frames, lighting poles, water and oil tanks and concrete repairs.

\section{MATERIALS AND MIX DESIGN}

\section{Materials used:}

Concrete is the most widely used construction material. The basic materials of concrete are Portland cement, water, fine aggregates i.e. sand and coarse aggregates. The cement and water form a paste that hardens and bonds the aggregates together. Concrete in fresh state is plastic and can be easily moulded to any shape, as time passes it hardens and gains strength. The initial gain in strength is due to a 


\section{International Journal of Engineering Applied Sciences and Technology, 2019 Vol. 4, Issue 3, ISSN No. 2455-2143, Pages 349-352 \\ Published Online July 2019 in IJEAST (http://www.ijeast.com)}

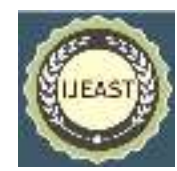

chemical reaction between water and $\mathrm{C} 2 \mathrm{~s}$ and latter gain in strength is due to reaction between $\mathrm{C} 3 \mathrm{~s}$ and water. Concrete is produced by either following nominal mix proportions in which the mix proportions are fixed as per grade of concrete required or mix design proportions, latter produces more economical concrete.

In our work Portland slag cement (PSC) -43 grade Konark cement was used. Standard consistency, initial setting time, final setting time, 28-day compressive strength tests were carried out as per the Indian standard specifications. Clean river sand passing through $4.75 \mathrm{~mm}$ sieve was used as fine aggregates. The specific gravity of sand was 2.68 and grading zone of sand was zone 3 as per IS .Angular stones were used as coarse aggregates maximum size $20 \mathrm{~mm}$ and specific gravity 2.72.Concrete was mixed and cured by ordinary water or tap water.

Cement is an extremely ground material having adhesive and cohesive properties which provide a binding medium for the discrete ingredients. The processes used for manufacture of cement can be classified as dry and wet.. The cement commonly used is Portland cement, it is also defined as hydraulic cement, i.e. a cement which hardens when it comes with water due to chemical reaction but there by forming a water resistant product. Portland cement is obtained when argillaceous and calcareous materials are grounded to fine powder and mixed in definite proportion and fused at high temperature. When blast furnace slag is also used as one of the ingredients than the cement obtained is called Portland slag cement (PSC). Portland slag cement (PSC) - 43 grade (Konark Cement) was used for the experimental programme.

Aggregates are generally obtained from natural deposits of sand and gravel, or from quarries by cutting rocks. The least expensive among them are the regular sand and rock which have been lessened to present size by characteristic specialists, for example, water, wind and snow and so on. The stream stores are the most well-known and are of good quality. The second most regularly used source of aggregates is the quarried rock which is reduced to size by crushing. The size of aggregates used in concrete range from few centimetres or more, down to a couple of microns. Fine aggregates is the aggregate most of which passes through a $4.75 \mathrm{~mm}$ IS sieve and contains just that much coarser material as allowed by the IS details. The fine aggregate used for the experimental programme was obtained from river bed of Koel. The fine aggregate passed through 4.75 $\mathrm{mm}$ sieve and had a specific gravity of 2.68 . The sand belonged to zone III as per IS standards.

The Coarse aggregates the vast majority of which are held on $4.75 \mathrm{~mm}$ IS sieve and contains just that a lot of fine material as is allowed by the code specifications are termed as coarse aggregates. The coarse aggregates may be crushed gravel or stone obtained by the crushing of gravel or hard stone; uncrushed gravel or stone resulting from natural disintegration of rock and partially crushed gravel or stone obtained as a product of the blending of the naturally disintegrated and crushed aggregates. In our case crushed stone was used with a nominal maximum size of $20 \mathrm{~mm}$ and specific gravity of 2.78 .

Water is the one most essential element of cement. Water assumes the vital part of hydration of concrete which frames the coupling lattice in which the dormant totals are held in suspension medium until the grid has solidified, furthermore it serves as the lubricant between the fine and coarse aggregates and makes concrete workable.

Fibre is a natural or synthetic string or used as a component of composite materials, or, when matted into sheets, used to make products such as paper, papyrus, or felt. Concrete is brittle bynature and is weak in flexure as well as direct tension therefore in order to improve this properties fibres are added to concrete. Fibres may be short discrete or in forms of rods or may be even in form of textile fibres or woven mesh fibres. Various types of fibres have been added to concrete some have high modulus of elasticity some have low modulus of elasticity each category can improve certain properties of concrete. In our case short discrete glass fibres were used and as glass fibre is susceptible to alkali we used alkali resistant glass fibres. A fiber is a material made into a long filament with a diameter generally in the order of $10 \mathrm{tm}$. The main functions of the fibers are to carry the load and provide stiffness, strength, thermal stability, and other structural properties in the FRC.

Glass strands are filaments generally utilized as a part of the maritime and mechanical fields to create composites of medium-elite. Their unconventional trademark is their high quality. Glass is basically made of silicon $(\mathrm{SiO} 2)$ with a tetrahedral structure (SiO4). Some aluminum oxides and other metallic particles are then included different extents to either facilitate the working operations or change a few properties (e.g., S-glass strands show a higher 


\section{International Journal of Engineering Applied Sciences and Technology, 2019 \\ Vol. 4, Issue 3, ISSN No. 2455-2143, Pages 349-352 \\ Published Online July 2019 in IJEAST (http://www.ijeast.com)}

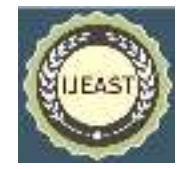

elasticity than E-glass).

Admixtures are the chemical compounds that are used in concrete other than hydraulic cement (OPC), water and aggregates, and can also be called as mineral additives that are added to the concrete mix just before or during blending to adjust one or more of the particular properties of the concrete in the fresh or hardened state. The utilization of admixture is necessary to offer a change which is not financially achievable by changing the extents of water, cement and though not influencing the performance and durability of the concrete. Usually used admixtures are accelerating admixtures, retarding admixture, airentraining admixtures and water-reducing admixture. In our case a water reducing admixture was used to obtain the desire workability as with increase in fibre content the mixture was becoming stiffer.

The experimental work consists of casting cubes, cylinders and prisms to study the effect of glass fibres on the compressive, flexural and split tensile strength of concrete. The effect was studied by varying the fibre content from $0 \%$ to $0.3 \%$, no water reducing admixture was used for the experimental programme. To check the effect on concrete for fibre content variation 6 specimens each of cube, prisms and cylinders were casted. Test were conducted on the specimen after 7 days and 28 days.

Further in order to get a practical use of glass fibres in concrete, concrete tiles were casted.The size of the tiles being $400 \mathrm{~mm} * 400 \mathrm{~mm} * 20 \mathrm{~mm}$. The maximum size of aggregates used for $8 \mathrm{~mm}$ in case of tiles and the testing for tiles were done as per IS $1237: 2012$. The fibre content varied from $0 \%$ to $0.7 \%$ and the main study of interest was compressive strength, wet transverse strength and water absorption.

\section{EXPERIMENTAL WORKS AND RESULTS}

\section{Compressive Strength of Concrete (in $\mathrm{N} / \mathrm{mm}^{2}$ )}

The 7 days compressive strength was studied and the values of 3 samples studied are shown in the tabular form. Table 1 shows the data of 7 days compressive strength obtained. Table 1 gives the 7 day compressive strength of concrete with maximum nominal size of aggregates $20 \mathrm{~mm}$. The 7 days compressive strength was also plotted Fig2 by taking the average of this three values overall an increase in the compressive strength was observed with addition of fibers.
Table 1: 7days compressive strength of concrete

\begin{tabular}{|l|l|l|l|l|}
\hline $\begin{array}{l}\text { Serial } \\
\text { number }\end{array}$ & $\begin{array}{l}\text { Without } \\
\text { fibre }\end{array}$ & $\begin{array}{l}0.1 \% \\
\text { fibre }\end{array}$ & $0.2 \%$ & $0.3 \%$ \\
\hline 1 & 16.89 & 17.77 & 21.33 & 22.22 \\
\hline 2 & 16.44 & 17.33 & 20.88 & 22.67 \\
\hline 3 & 16.44 & 17.33 & 21.33 & 23.11 \\
\hline
\end{tabular}

\section{Split Tensile Strength comparison (in $\mathrm{N} / \mathrm{mm}^{2}$ )}

The 7 days Split Tensile strength was studied and the values of 3 samples studied are shown in the tabular form. Table 3 shows the data of 7 days compressive strength obtained. Table 3 gives the 7 days compressive strength of concrete with maximum nominal size of aggregates 20mm.The 7 days compressive strength was also plotted Fig4 by taking the average of this three values overall an increase in the compressive strength was observed with addition of fibers.

Table 2: 7days Split Tensile Strength of Concrete

\begin{tabular}{|l|l|l|l|l|}
\hline $\begin{array}{l}\text { Serial } \\
\text { number }\end{array}$ & $\begin{array}{l}\text { Without } \\
\text { fibre }\end{array}$ & $0.1 \%$ & $0.2 \%$ & $0.3 \%$ \\
\hline 1 & 1.485 & 1.84 & 2.405 & 2.405 \\
\hline 2 & 1.626 & 1.70 & 2.26 & 2.405 \\
\hline 3 & 1.45 & 1.84 & 2.26 & 2.263 \\
\hline
\end{tabular}

\section{Flexural Tensile Strength (in $\mathrm{N} / \mathrm{mm}^{2}$ )}

The 7 days Flexural Tensile strength was studied and the values of 3 samples studied are shown in the tabular form.Table 5 shows the data of 7 days flexural tensile obtained. Table 5 gives the 7 day compressive strength of concrete with maximum nominal size of aggregates 20mm.The 7 days compressive strength was also plotted Fig6 by taking the average of this three values overall an increase in the compressive strength was observed with addition of fibers. 


\section{International Journal of Engineering Applied Sciences and Technology, 2019 \\ Vol. 4, Issue 3, ISSN No. 2455-2143, Pages 349-352 \\ Published Online July 2019 in IJEAST (http://www.ijeast.com)}

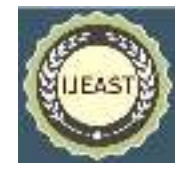

Table3: 7 days Flexural Strength of Concrete

\begin{tabular}{|l|l|l|l|l|}
\hline $\begin{array}{l}\text { Serial } \\
\text { number }\end{array}$ & $\begin{array}{l}\text { Without } \\
\text { fibre }\end{array}$ & $0.1 \%$ & $0.2 \%$ & $0.3 \%$ \\
\hline 1 & 4.6 & 4.744 & 4.988 & 5.744 \\
\hline 2 & 4.7 & 4.776 & 4.988 & 5.424 \\
\hline 3 & 4.8 & 4.756 & 4.9 & 5.704 \\
\hline
\end{tabular}

\section{CONCLUSIONS}

In this experimental program the effect of short discrete glass fibers on the compressive,split tensile strength and flexural strength of concrete was studied.

- The effect of glass fibres on cement and concrete tiles which are produced by vibration method are also studied. The properties studied are compressive strength, wet transverse strength and water absorption. The concrete mix gets harsher and less workable with increase of fiber content therefore use of admixture become necessary. However even after giving dosage of admixture as high as $1.5 \%$ proper workability could not be obtained and some segregation was observed. Therefore it was not possible to go beyond $0.7 \%$ fiber content.

- The various observation based on the experimental result are as follows:

- The compressive strength of concrete without admixture is not affected by the presence of short discrete glass fibers with fibre content in the range 0.1 to $0.3 \%$ of fiber content by weight of concrete.

- The split tensile strength of concrete increases with the addition of glass fibers.

- The flexural strength of concrete increases with increase in fiber content and as such the tension carrying capacity of concrete may increase in flexure

- The wet transverse strength of tiles increases and the increase has been found with addition of fibers

- The water absorption of the concrete also decreases with increase in fiber content.

- The compressive strength of concrete with admixture was not affected upto $0.4 \%$ fiber content but decreased with the presence of higher amount of fibers.

\section{REFERENCES}

1. Perez-Pena .M and Mobasher .B, "Mechanical properties of fiber reinforced lightweight concrete composites ". Cement and Concrete Research, Vol. 24, No. 6, pp. 1121-1132, 1994

2. Brandt AM. "Cement-based composites: materials, mechanical properties and performance". London: E\&FN Spon; 1995. p. 470

3. Nakamura H, Mihashi H. "Evaluation of tension softening properties of fiber reinforced cementitious composites." Fracture Mechanics of Concrete Structures 1998; I:499e510.

4. Mirza F.A., Soroushiannd P. "Effects of alkaliresistant glass fiber reinforcement on crack and temperature resistance of lightweight concrete." Cement and Concrete Composites 2002;24(2):223-7

5. Robert S.P. Coutts .A review of Australian research into natural fibre cement composites" Cement \& Concrete Composites 27 (2005) 518526

6. Khosrow Ghavami. "Bamboo as reinforcement in structural concrete elements" .Cement \& Concrete Composites 27 (2005) 637-649

7. Huang Gu, Zuo Zhonge "Compressive behaviour of concrete cylinders reinforced by glass and polyester filaments". Materials and Design 26 (2005) 450-453

8. Andrzej Brandt .M "Fibre reinforced cementbased (FRC) composites after over 40 years of development in building and civil engineering". Composite Structures 86 (2008) 3-9

9. Luiz C. Roma Jr., Luciane S. Martello, Holmer Savastano Jr ."Evaluation of mechanical, physical and thermal performance of cementbased tiles reinforced with vegetable fibers". Construction and Building Materials 22 (2008) 668-674

10. Filho Toledo Dias Romildo, Andrade Silva Flavio de, Fairbairn E.M.R.."Durability of compression molded sisal fiber reinforced mortar laminates". Construction and Building Materials 23 (2009) 2409-2420

11. Wu. Y.-F. "The structural behaviour and design methodology for a new building system consisting of glass fiber reinforced gypsum panels" Construction and Building Materials 23 (2009) 2905-2913 